\title{
Feasibility and Operating Costs Of An Air Cycle For CCHP In A Fast Food Restaurant
}

\author{
H. Perez-Blanco \\ hpb1@gmail.com \\ Mechanical and Nuclear Engineering \\ Penn State
}

\author{
Edward Vineyard \\ vineyardea@ornl.gov
}

Computational Sciences and Engineering Division Oak Ridge National Laboratory

\section{$\underline{\text { Abstract }}$}

This work considers the possibilities of an air-based Brayton cycle to provide the power, heating and cooling needs of fast-food restaurants. A model of the cycle based on conventional turbomachinery loss coefficients is formulated. The heating, cooling and power capabilities of the cycle are extracted from simulation results. Power and thermal loads for restaurants in Knoxville, TN and in International Falls, $\mathrm{MN}$, are considered. It is found that the cycle can meet the loads by setting speed and mass flow-rate apportionment between the power and cooling functional sections. The associated energy costs appear elevated when compared to the cost of operating individual components or a more conventional, absorption-based CHP system. A first-order estimate of capital investments is provided. Suggestions for future work whereby the operational costs could be reduced are given in the conclusions.

$\begin{array}{ll}\text { Nomenclature } & \\ a_{x y z} & \text { Coefficients } \\ A & \text { Duct area, }{ }^{2} \\ a h & \text { Absolute humidity } \\ c p & \text { Specific heat, } \mathrm{J} / \mathrm{kg}^{*} \mathrm{~K} \\ C H P & \text { Combined heat and power. } \\ c t & \text { Cooling turbine } \\ D & \text { Diameter, } \mathrm{m} \\ D F & \text { Diffusion factor } \\ F M & \text { Figure of merit for CHP. } \\ h & \text { Specific enthalpy, J/kg } \\ \Delta h_{v f} & \text { Specific enthalpy of vaporization, J/kg } \\ k & \text { Isentropic exponent } \\ m f r & \text { Mass flow rate, kg/s } \\ M & \text { Mach no. } \\ M_{i e} & \text { Tip Mach no. } \\ N V & \text { Number of vanes. } \\ O A & \text { Outdoor air } \\ p & \text { Pressure, Pa. } \\ p t & \text { Power turbine } \\ P R & \text { Pressure ratio } \\ P M & \text { Primary energy } \\ Q & \text { Heat, kJ } \\ \dot{Q} & \text { Heat rate, kW } \\ R & \text { Radius, m } \\ R a & \text { Air Gas constant, kJ/kg.K } \\ R A & \text { Return air } \\ S & \text { Specific entropy, } \mathrm{kJ} / \mathrm{kg} \cdot \mathrm{K} \\ S A & \text { Supply air } \\ S u & \text { Summer } \\ S P R & \text { Rotational speed ratio } \\ S C C H P & \text { Seamless cooling combined heat and power } \\ T & \text { Absolute temperature, K. } \\ T C A & \text { Cooling turbine air } \\ T H A & \text { Power turbine air } \\ & \end{array}$




$\begin{array}{ll}U & \text { Metal velocity, } \mathrm{m} / \mathrm{s} \\ V & \text { Absolute velocity, } \mathrm{m} / \mathrm{s} \\ V f r & \text { Volume flow rate, } \mathrm{m}^{3} / \mathrm{s} \\ V_{s} & \text { Velocity of sound, } \mathrm{m} / \mathrm{s} \\ V_{s p t} & \text { Spout velocity, } \mathrm{m} / \mathrm{s} \\ W & \text { Work, } \mathrm{kJ} ; \text { relative velocity, } \mathrm{m} / \mathrm{s} \\ W i & \text { Winter } \\ \dot{W} & \text { Mechanical power, } \mathrm{kW} \\ \text { Greek Letters } & \\ \beta & \text { Vane angle } \\ \varepsilon & \text { Recuperator thermal effectiveness } \\ \eta & \text { Isentropic efficiency } \\ \rho & \text { Density, kg/m }{ }^{3} \\ \sigma & \text { Slip coefficient } \\ \omega & \text { Angular velocity, } 1 / \mathrm{s} \\ \text { Super and subscripts } \\ \cdot & \text { Indicates rate. } \\ a & \text { Humid air } \\ c & \text { Compressor } \\ C & \text { Cooling } \\ c t & \text { Cooling turbine } \\ e & \text { Exit } \\ e f f & \text { Effective, required. } \\ H & \text { Heating } \\ i & \text { inlet } \\ i n p & \text { input } \\ o & \text { Stagnation conditions } \\ p t & \text { Power turbine } \\ r & \text { Reference or relative; radial direction } \\ s & \text { Isentropic, or sound } \\ s t & \text { Steam } \\ t & \text { Turbine } \\ u & \text { Azimuthal } \\ & \end{array}$

\section{Introduction: Why the Brayton cycle}

Brayton cycle-based gas turbines are used for aircraft propulsion and for ground-based power generation. Their dynamic response and fuel efficiency plus ability to operate at high altitudes have made them the engine of choice for almost all types of aircraft. The low heat rates, load-following capabilities, together with straightforward permitting have made them a definitive player in the power generation arena.

Aircraft cabins flying at high altitudes or in cold days on the tarmac need heating for comfort and operability. When flying low altitudes or in a hot day on the tarmac, cabins need cooling air. To provide heating, engine compressor air is used for heating via valves controlling the discharge rate and stage. Compact $A / C$ units operating on reverse Brayton cycles are used to provide chilled air [1]. Some aircraft have conventional air conditioners, but the simplicity and direct application of the air cycles currently dominate the aircraft heating and cooling industry.

The Brayton (power and heating) and reverse Brayton cycle (cooling) are described briefly in this paragraph and the next. Air is assumed to be a perfect gas, and ideal standard cycles are considered for description. In a T-s diagram, (Fig 1), the constant pressure lines are shown schematically. Air at ambient conditions is compressed isentropically, (1c to 2pt), heated (2pt to 1pt) and expanded in a turbine (1pt-3pt). The air can be delivered directly for heating, or cooled to 1c to recommence the cycle. In aircraft, pressurized and hot air is obtained from state points between $1 \mathrm{c}$ and $2 \mathrm{pt}$. In real turbines, the 
process 2 pt-1pt includes combustion, whereby the mixture at $3 p t$ is unsuitable for use in conditioned spaces and constitutes the exhaust of the engine.

A particularity of the T-s diagram is that the vertical spacing between two constant pressure lines increases (exponentially, in fact) with absolute temperature. For a perfect gas undergoing an adiabatic compression or expansion, the power exchanged is given by

$$
\dot{W}=m f r \cdot c p \cdot\left(T_{\text {final }}-T_{\text {initial }}\right)
$$

Since the turbine temperature difference (1pt-3pt) is greater than the one in the compressor (1c-2pt), it follows from Eq 1 that the power delivered by the Brayton cycle turbine exceeds that required by the compressor, and the turbine can drive a fan or generator. In the reverse Brayton cycle, the air is compressed ( $1 \mathrm{c}$ to $2 \mathrm{c}$ ), cooled close to ambient (2c to 3c) and expanded (3c to 4c). The cooling cycle needs to receive external power for sustained operation, as could be concluded from Eq 1 . The chilled air can be delivered to the conditioned space, previous to dehumidification at an opportune point in the cycle.

The reverse Brayton cycle has been proposed for a number of $A / C$ applications. For racing car settings, where light weight and simplicity are of importance, Foster and Lemieux [2] implemented and tested an automotive cooling system using automotive turbocharger components. Compressor pressure ratios of 1.7 at speeds bordering $110,000 \mathrm{rpm}$ were reported. With dry air the cooling COP hovered around 0.38 with a capacity of $1.6 \mathrm{~kW}$. Whereas the COP is not high, the work showed the feasibility of using existing components to produce cooling . Another novel cooling application is suggested in [3], where it is proposed to use the reverse Brayton cycle to cool the inlet air stream into a gas turbine. Cooling the inlet stream reduces the heat rate and increases the capacity of the machine. The extra cooling power is calculated to be smaller than the increment of power due to inlet cooling. In this case, by cooling the air stream with seawater a net power gain in the order of $19 \%$ is projected.

Brayton cycles can be used for simultaneous production of heating and cooling. In [4], an experimental system was developed to ascertain if air for at freezing and cooking could be provided using compressor air and a reverse Brayton cycle. Functionally the somewhat complicated arrangement worked well: cooling loads ranging from 1.7 to $3.6 \mathrm{~kW}$ at temperatures between $-140 \mathrm{C}$ to $-80 \mathrm{C}$ were obtained. The total heating load provided was in the order of $40 \mathrm{~kW}$, at temperatures ranging from 60 to $150 \mathrm{C}$. This study proved that food processing applications could be well served by an air cycle. An interesting article by Fleming et al. [5] developed a procedure for systematic evaluation of air heating and cooling systems. The paper also reports on a reverse Brayton refrigeration cycle that was working well at the time.

Trigeneration consists of the simultaneous generation of power, heating and cooling. Such simultaneity is the key to high efficiencies and lower $\mathrm{CO}_{2}$ production. In general, schemes based on Brayton cycles employ microturbines as prime movers [6]. The combustion products from the turbine are used for thermal production (steam or hot water) and also activate an absorption unit for chilling. This useful review [6] contains a plethora of prime movers and of cooling technologies to achieve trigeneration. One interesting observation from [6] is that in some instances, an electric chiller instead of an absorption one is considered. Whereas there is no universal conclusion as to which is the best route to pursue, a higher exergy efficiency seems to be the province of installations with absorption chillers.

In this paper, we investigate the potential of a Brayton cycles to provide trigeneration to a fast food restaurant. Fast food restaurants are generally difficult environments to condition, due to the large and short load peaks, and due to the requirements for ample make-up air. Load data are derived for two locations: one in the "mixed-humid" climate zone [7], namely Knoxville, TN, and one in the "cold/very cold" zone [7], namely International Falls, MN. The selection of these communities is not arbitrary: The mixed-humid climate exhibits extreme summer and winter loads. The ability of the cycle to provide power and heat simultaneously led us to International Falls, one of the coldest cities with available loads as per the news [8]. 
The cycle considered to meet the needs of the restaurants is shown schematically in Fig 2. The power turbine drives the compressor jointly with the cooling turbine. Air enters the compressor at 1c, (Figs 2 or 1 ), and it is compressed to $2 \mathrm{ct}=2 \mathrm{pt}$. The air routed to the power turbine is preheated (2pt to 2apt) and is heated externally from 2 apt to $1 \mathrm{pt}$. The power turbine air is expanded (1pt to 3pt), and cooled to $4 \mathrm{pt}$ before being released to heating duty.

Excess power is used for electrical generation. The air routed to the cooling turbine is cooled by atmospheric air from $2 \mathrm{ct}$ to $1 \mathrm{ct}$, and cooled via expansion to 3ct. Assuming supersaturated air at $3 \mathrm{ct}$, all moisture could be removed mechanically to yield cold and dry air at 4ct.

The objective of the work is to ascertain the potential of the trigeneration cycle (hereby called SCCHP) by creating a model that will

a. Reflect reasonable dimensions for the three wheels.

b. Estimate reasonable isentropic efficiencies at varying speeds

c. Allow for variations of speed and required utilities for varying inlet conditions.

d. Estimate the costs of generating the utilities.

A basic evaluation is sought, and simple models are preferred for this purpose. After the model is presented, results are shown and summarized. The rudiments of capital and operational costs are presented to enable a first-order financial appraisal of SCCHP.

\section{Models}

To meet our objectives, models of radial turbomachines and heat exchangers are needed. Efficiencies and mass flow rates at full and partial loads are incorporated in the models.

\subsection{Compressor}

The pressure ratio, mass flow rate and isentropic efficiency are the main variables. All variables depend on the tip velocity, given by:

$$
U_{2}=\omega \cdot R_{2}
$$

The impeller slip coefficient is adopted as:

$$
\sigma=1-1.98 \cdot \cos (\beta 2) / N v
$$

Other variables defining the impeller performance are the inlet relative Mach number $M 1 r$, used to estimate the relative inlet velocity, Eq 4 .:

$$
W_{1}=M_{1 r} \cdot V_{s 1} \cdot S P R
$$

Where the speed ratio SPR is a simulation input. The speed of sound is estimated as:

$$
V_{s 1}=\sqrt{k \cdot R_{a} \cdot T_{o 1}}
$$

The work done on the flow and the speed triangle at the impeller exit are used to estimate the discharge stagnation and static temperatures. The power input to the flow is given by:

$$
\dot{W}_{\text {flow }}=m f r_{c} \cdot U_{2} \cdot V_{u 2} \cdot \sigma
$$

Where the azimuthal velocity $V_{u 2}$, as well as the absolute velocity $V_{2}$ and its radial component $V_{r 2}$ comply with the impeller exit velocity triangle. Such compliance calls for an estimate of the relative exit velocity $W_{2}$, namely:

$$
W_{2}=D F \cdot W_{1}
$$


Key to the impeller treatment is the exit stagnation temperature, which complies with Eq 8, namely:

$$
T_{o 2}=T_{o 1}+W_{\text {flow }} /\left(c p_{a} \cdot m f r_{c}\right)
$$

Often, Eq 6 is modified by the addition of the "work done factor", reflecting windage and flow recirculation losses. For simplicity, we rely only on an overall isentropic efficiency. The kinetic energy imparted to the flow is transformed into pressure and some thermal energy in the diffuser. The isentropic efficiency, stagnation temperatures and pressure ratios are related by:

$$
T_{2^{\prime}}=T_{o 1}+\eta_{c} \cdot\left(T_{02}-T_{01}\right)
$$

The isentropic efficiency $\eta_{c}$ is difficult to project. Assuming that a suitable value is available to calculate $T_{2}$, then Eq 10 gives the sought pressure ratio:

$$
\frac{P_{02}}{P_{01}}=P R=\left(\frac{T_{2^{\prime}}}{T_{01}}\right)^{\frac{k}{k-1}}
$$

The difficulty of the adopted approach is to produce a suitable isentropic efficiency for use in Eq. 9. The topic is an important one, and many estimating approaches exist. Some authors [9] offer generic compressor maps of pressure ratios vs. flow, with constant efficiency contours. Others offer composite correlations [10], reflecting many compressors in the market. The said correlations depend on a universal parameter, the tip-inlet Mach number, $M_{i e}$. This parameter is defined as the tip velocity divided by the speed of sound at the inlet stagnation conditions,

$$
M_{i e}=\frac{U_{2}}{V s_{01}}
$$

A simpler (if coarser) approach is deemed more conducive to our first-order evaluation. Efficiency equations and suitable coefficients were adapted from [11]. For a fixed inlet $M$ number, the following correlation is used, based on the form developed in [11]:

$$
\eta_{c}=0.04+0.15 \cdot \log (P R)+1.12 \cdot M_{2}-0.5 \cdot\left(M_{2}\right)^{2.5}
$$

The mass flow rate for the compressor reflects the decreasing pressure ratio with increasing flows for this type of machine, and in our case it is assumed to follow:

$$
m f r_{c}=7.915 \cdot(S P R)^{1.9}-\left(\frac{V f r^{2}}{0.2 \cdot\left(m^{6} / s^{2}\right)}\right)
$$

\subsection{Turbines}

Nozzles accelerate the flow at the expense of a pressure drop. The moving flow activates a runner, connected to the common shaft. A schematic of a radial turbine with the state points of the power turbine is given in Fig 4. The vane angle is $90^{\circ}$.

Key variables (in addition to speed, specified by the user) are the tip velocity, the spout velocity and the turbine efficiency. The spout velocity, given by:

$$
V_{s t p}=\sqrt{2 \cdot c p \cdot T_{o, 1 p t} \cdot\left(1-\frac{1}{P R} \frac{\left(\frac{k-1}{k}\right)}{k}\right)}
$$

together with the tip velocity and the turbine discharge velocity $V_{3, p t}$ :

$$
V_{3, p t}=\frac{m f r_{p t}}{\left(\rho_{3, p t} \cdot A_{3}\right)}
$$

define two important parameters, namely: 


$$
\arg _{1}=\frac{U_{2, p t}}{V_{s t p, p t}} \quad \quad \arg _{2}=\frac{V_{3, p t}}{U_{2, p t}}
$$

These parameters lead to calculations of an inlet area, proportional to the valve area required to accommodate the turbine flow. The mass flow rate must comply with the nozzle equation proposed in [13]:

$$
m f r_{p t, e f f}=A_{e f f} \cdot \sqrt{\left(\frac{k}{R a}\right)^{0.5} \cdot P R^{\frac{1}{k}} \cdot \frac{2}{k-1} \cdot\left(1-\frac{1}{P R^{\frac{k-1}{k}}}\right)}
$$

It should be noted that the units of $m f r_{p t, e f f}$ are $m \cdot s \cdot K^{0.5}$. When this parameter is multiplied by the inlet pressure and divided by the square root of the inlet temperature, one obtains the mass flow rate. The effective area, $A_{\text {eff, }}$ is a function of the speed ratio arg1, the turbine rating, and the actual rotational speed [13]. A correlation of all these variables for all possible turbines is definitely a difficult undertaking, and hence the following approximation is used:

$$
A_{\text {eff }} / A_{\text {design }}=-0.315 \cdot \arg _{1}+0.57
$$

The value of $A_{\text {eff }}$ decreases with arg1, which seems to be universal for all radial turbines[11]. However, Eq 18 it does not fit any particular turbine, and the speed dependence of the area ratio is ignored. $A_{\text {design }}$ is simply the area that ensures a mass flow rate of $0.5 \mathrm{~kg} / \mathrm{s}$ (design), for the design inlet pressure and temperature.

As the speed of the turbine varies, its efficiency will vary as well. The efficiency map given in [12] is adopted here. It reflects the variation of efficiency with the two ratios of Eq 16 . Whereas it is not an universal map, it does reflect decreases in efficiency as the parameters depart from the optimal values $(\arg 1=0.7, \arg 2=0.25) \quad$ The correlation for efficiency is recorded via Table 1 and Eq 19 below.

The coefficients of Table 1 are used in Eq 19 to estimate the turbine efficiency.

$\eta_{p t}=a_{0}+a_{1} \cdot \arg 1+a_{2} \cdot \arg _{2}+a_{12} \cdot \arg g_{1} \cdot \arg _{2}+a_{11} \cdot \arg _{1}^{2}+a_{22} \cdot \arg _{2}^{2}+a_{112} \cdot \arg _{1}^{2} \cdot \arg _{2}+a_{122} \cdot$

$\arg _{1} \cdot \arg _{2}^{2}+a_{111} \cdot \arg _{1}^{3}+\arg _{222} \cdot \arg _{2}^{3}$

The estimated efficiency is used to determine the exit temperature, Eq 20:

$$
T_{3 p t}=T_{0,1 p t}-\eta_{t} \cdot\left(T_{0,1 p t}-T_{3, s}\right)
$$

The cooling turbine model follows essentially the same approach as the one outlined for the power turbine.

Small generators ( 40 to $60 \mathrm{kVA}$ ) can have large efficiencies at a given speed [14], 90 to $93 \%$. At other speeds the efficiency may vary, but it is assumed constant at $91 \%$. An inverter for frequency shifting is assumed.

\subsection{Recuperator and thermal loads}

The recuperator in Fig 2 is modelled as per the effectiveness-NTU method [14] for a counterflow configuration. The larger heat capacity in this exchanger is that of the hot stream, due to a higher specific heat. The exit temperature $T_{2 a p t}$, necessary to establish the cycle heat input, is given by:

$$
T_{2 a p t}=T_{2 p t}+\varepsilon \cdot\left(T_{3 p t}-T_{2 p t}\right)
$$

$T_{4 p t}$ is simply obtained from a heat balance around the recuperator. The heating capacity is assumed equal to the heat released when cooling the gases to a temperature of $T_{\text {hmin }}$, namely: 


$$
\dot{Q_{H}}=m f r_{p t} \cdot c p_{a} \cdot\left(T_{4 p t}-T_{h m i n}\right)
$$

Evaluation of the potential cooling capacity is more involved. The discharge cooling turbine temperature could be as low as $-73 \mathrm{C}$ (i.e. $200 \mathrm{~K}$, or $\sim-100 \mathrm{~F}$ ). Humid air enthalpies are calculated as:

$$
h=c p_{a} \cdot T+a h \cdot\left(c p_{s t} \cdot T+\Delta h_{v f, s t}\right)
$$

Consideration is given to different possibilities on how to use the cold air. In the direct injection mode, Fig 5, the cold air from the turbine (TCA) goes through a moisture separator (likely of the centrifugal type), and it is directly injected into the space as both make-up and conditioning air. The $R A$ stream must equal the $S A$ stream. To avoid unsightly and possibly dangerous cold streams in direct injection, a new air distribution system must be conceived and designed.

Assuming that such system could be built, the equivalent cooling capacity is easily estimated. Assuming the $R A$ and $S A$ conditions of Table 2, the capacity is estimated as the thermal (latent and sensible) energy absorbed by the SA stream as it approaches the RA conditions.

The equation used for this purpose is then:

$$
Q_{\max }=m f r \cdot\left(h_{R A}-h_{S A}\right)
$$

In a conventional air distribution system, the $S A$ conditions are generally well defined in HVAC practice (saturated at $15 \mathrm{C}$ ). They are obtained by mixing the stream from the cooling turbine TCA (Fig 6), with outdoor air $(O A)$ and if necessary hot air from the power turbine, THA. In our simulations, the THA is usually rendered null by adjusting the TCA conditions, by adjusting $T_{1 c t}$ in turn. Implementation of the system of Fig 6 would be much simpler than that of Fig 5. Retrofit applications would fit the Fig 6 model.

\subsection{System variables at nominal speed}

Upon simulation, the system was projected capable of operating as per Table 3.

The components were integrated into an EES [15] program, with a main program for input/output of relevant values, and eleven subprograms or procedures for the equipment and loads. Inputs are speed, cooling and power flows, and inlet conditions to compressor and turbines. Outputs are the thermal and power loads, and the net power generated.

\section{Results}

\subsection{The effect of rotational velocity}

In an actual application, the torque of each machine would determine the resultant speed. Increasing the inlet turbine temperatures or the generator load would result on a different speed. The compressor determines the pressure ratio, which in turn determines the turbine power outputs. The graph of pressure ratio vs. speed shows a parabolic dependence, Fig 7.

The SCCHP model is found to converge well for all the speeds considered. The possibility of surge or choke was not incorporated in the program, but close attention was paid to maps such as those in [9], to avoid regions of high PRs with small flows for the compressor. The mass flow rates are calculated from the adopted wheel variables and speed. The variations of flow rates with speed are shown in Fig 8 . The cooling turbine accepts increased flows with speed, in order to supply an increasing cooling load. The power turbine receives decreasing flows at decreasing speeds. At design, each turbine receives the same flow. 
To calculate the cooling capacity standard $S A$ is assumed. The $S A$ conditions are adjusted as to render the THA null, as already explained. The cooling capacity is shown in Fig 9. The maximum cooling capacity by direct injection is roughly twice the capacity shown here.

The response of power to speed is shown in Fig 10. As the ct mass flow rate and inlet temperature increase with speed so does the power developed by the machine. The pt power decreases with speed, because its inlet temperature is constant while the flow rate decreases (Fig 8). Also, the pressure ratio of the compressor increases with speed, and this adds both to the compressor power requirements and to the turbines power. The relatively low compressor isentropic efficiency subtracts from net power generation. The net power can be increased to the detriment of the cooling power, by adjusting the mass flow rates.

\subsection{Thermal and power loads}

In order to determine whether the SCCHP air cycle could follow the loads of a fast food restaurant, a site in the Knoxville area was chosen from the many buildings types in a DOE database [17]. The characteristics of this building are summarized in Table 4.

The load profiles for every day of the year have been calculated and are given in [16]. The loads are for power for general uses, power for $\mathrm{A} / \mathrm{C}$, space heating, hot water and cooking. To translate the purchased utility values [16] into actual loads in kW, efficiencies and COPs of cooling units are assumed. The gas furnace efficiency and A/C COP were assumed to peak at 0.93 and at 4 respectively, with small variations for outdoor temperatures. The loads obtained for Wi and Su days are shown respectively in Figs 11 and 12.

In Wi, at $5 \mathrm{hrs}$ the heating load peaks at $38.7 \mathrm{~kW}$, while the power load is $11.5 \mathrm{~kW}$. In the same day, the electric load peaks at $19 \mathrm{hrs}$ at $26.1 \mathrm{~kW}$, with a heating load of $18.1 \mathrm{~kW}$. In Su, the A/C and power loads peak twice, with the max power being $27 \mathrm{~kW}$ and the max cooling $14 \mathrm{~kW}$. The Su heating load is small and relatively constant during the daytime. In the simulation, if the cooling load is met, it may happen that the power load is exceeded. There are cases when the speed and mass flow controls are sufficient to operate without importing or exporting power. The system is assumed to run continuously.

As mentioned above, the Wi day has two peaks of interest. The model is run at both conditions, to verify feasibility of supply. In order to match the electric loads, the speed is reduced, and the inlet air temperature is also reduced to reflect a Wi day. As it can be ascertained from Fig 13, the system can easily meet the power and thermal loads. At higher speed, it could actually export power.

The summer peaks of interest (Fig 12) occur at 5, 12 and 19 hours. The case of ordinary $S A$ is considered. When the model is run at the peak hours, it can meet the $A / C$ loads and the heating loads, but it can only provide power to meet site demands at 5 and 17 hours (Fig $14 \mathrm{~b}$ ). At 12 hrs, the system can reduce power purchases by $25 \%$, with most air devoted to cooling. The results of the simulation for conventional SA are condensed in Fig 14, (a) for the A/C load, and (b) for the power load. The heating load can be satisfied easily at all times.

When direct injection is considered, the A/C loads that can be met are large. In the Su day in Knoxville, not only the cooling load can be met, but the power generated could exceed the building requirements, and power could be injected into the grid at peak hours. The results are shown in Fig 15 (a) for A/C, and 15 (b) for power. It is clear that both the $\mathrm{A} / \mathrm{C}$ and power loads can be met at all times. 
Direct air injection opens a number of worthwhile, unexplored possibilities, centered on power generation. Stabilizing the grid, increasing owner's revenue and allowing for a different injection system with possibly no fans (i.e., decreasing the power consumption) is an intriguing route.

\subsection{Make-up air, operational costs and capital}

The SCCHP air cycle aspect of most interest is the direct delivery of fresh air. This must be compatible with the standards of $I A Q$, rather onerous in fast food restaurants. The exact make-up flow rate could not be ascertained from the available data. Fresh air needs are approximated. In cooling, the specified air flow [19] is about $2.20 \mathrm{~kg} / \mathrm{s}$ (1.37 kg/s for the dining area, and $0.83 \mathrm{~kg} / \mathrm{s}$ for the kitchen). The outdoor air flow varies between $1.37 \mathrm{~kg} / \mathrm{s}$ and $0.95 \mathrm{~kg} / \mathrm{s}$. In winter, the specified air flow is $1.79 \mathrm{~kg} / \mathrm{s}$, with a minimum of $0.83 \mathrm{~kg} / \mathrm{s} O A$. The kitchen requires $0.83 \mathrm{~kg} / \mathrm{s}$ of outdoor air all year round.

Then, at least $1 \mathrm{~kg} / \mathrm{s}$ of OA must be provided all year around. At the peak hours of 12 and $17 \mathrm{p} . \mathrm{m}$. in Su, the SCCHP fulfills the desired load with 0.51 and $0.42 \mathrm{~kg} / \mathrm{s}$ of fresh air. In the winter peak at $17 \mathrm{hrs}$, the air flow rate is $0.25 \mathrm{~kg} / \mathrm{s}$. Hence, the air cycle would not provide the make-up air as called for in [19]. Changing the $S A$ conditions could be a way to provide the desired flows. Yet, any additional mixing would increase irreversibilities, and with them, operational costs.

The peak hours addressed in Figs 13, 14 and 15 demand electricity for $\mathrm{A} / \mathrm{C}$, gas for water heating and electricity for all other electric contraptions. The SCCHP air cycle could provide the same utilities. Natural gas combustion products would be used to heat the power turbine air with a burner efficiency of 0.9. The hourly cost is calculated for each Su and Wi peak. The results are summarized in Table 5 . This table includes, in addition to the conventional system, a CHP system configured with a gas engine, absorption machine and heat recovery [6] for comparison. Because the engine capable of meeting the power load in Knoxville would be of $30 \mathrm{~kW}$ capacity, there is not always enough waste heat to drive the absorption machine or the heat recovery operation in W. Hence, extra gas is assumed to be purchased in order to meet the load.

The prices reflect the 2014 EIA averages. Excess electrical energy is credited at the prevalent price, although this excess is too small to change the SCCHP air cycle outlook. From the last three columns of Table 5, the hourly operational cost of the SCCHP is much larger than the cost of providing the separate utilities or the conventional CHP system with favorable electricity prices. This is the case for both Su and Wi days. Even when maximizing the SCCHP power production, the cost decreases only by about $\$ 2 / \mathrm{hr}$.

A similar restaurant in International Falls, $\mathrm{MN}$ is also characterized. From the hourly loads for a Jan $2^{\text {nd }}$ and July $31^{\text {st }}$ [22], peak hours are selected and the results of Table 6 are obtained. The air cycle can meet the loads, but the operational costs favor the individual purchase of power and heat. The differences between the conventional and SCCHP systems are smaller in International Falls than in Knoxville, due to the increased heating loads.

Another result concerns the air cycle versatility. Large $A / C$ loads can occur in fast food restaurants. For instance, during the month of July, $\mathrm{A} / \mathrm{C}$ loads in International Falls can reach a surprisingly high peak in the order of $25 \mathrm{~kW}$. Model modifications were undertaken to increase the cooling load capability. The compressor mass flow rate is increased to increase the cooling capacity. The inlet Mach number of the compressor is relaxed from 0.5 to 0.7 , and the mass flow rate is adjusted (Eq 13 constants). The former change could result on a cooler inlet temperature. The latter change is equivalent to increasing the discharge and diffuser width to accommodate the larger flow. With these changes, the system has larger flows, Table 7. 
Clearly, relatively small modifications can result in enhanced mass flow rates, with enhanced cooling capacity $(25.8 \mathrm{~kW})$ and a hefty net power $(25.2 \mathrm{~kW})$. Whereas many heating needs could be met, the heat input (last entry in Table 7) remains relatively large.

Regarding capital costs, additional assumptions are made. The conventional system consists of an A/C split, air cooled system, with a forced air furnace and a hot water heater. The parameters and capacities assumed for estimating the conventional costs are given in Table 8 . The SCCHP system is not currently manufactured, and extrapolation from micro turbines is adopted, Table 8 . It is assumed that the expansion turbine would add $50 \%$ to the direct cost of a microturbine, and that installation would be $50 \%$ of the purchase cost. The air distribution system cost is the same for both systems.

The conventional system has a small initial cost advantage over the CHP one. Whereas there is a high degree of uncertainty in capital costs, indication that both capital and operational costs favor the usual system seem apparent. The absorption system, being more complex, demands a higher capital cost but returns larger savings during peak hours, provided that the power returned to the grid is credited at a price not distant from the purchase price. Air-cooled machines seem available, but of lower capacity than required [29]. Assuming a return in the order of $\$ 1 / \mathrm{hr}$, the additional water-cooled investment could be paid in 3.25 yrs. Clearly, whereas outside our scope, the absorption system should receive additional consideration.

\section{Conclusion}

Air cycles have many enticements: direct delivery of conditioning air, no cooling water and the possibility of meeting IAQ requirements. In airplanes and other transportation applications, subsets of the cycle considered here (i.e. only the cooling section or heating with compressor air) have been accepted as the best option. The present study is undertaken to ascertain whether the air cycle enticements could apply to CHP.

The air cycle adopted here is the simplest possible one, and could rely on turbocharger technology of the IC engine industry. Models adopting conventional loss correlations for turbomachinery are implemented, and the results of simulation used to determine whether the SCCHP air cycle can meet the needs of a fast-food restaurants all year round.

It appears that by adjusting the speed, mass flow rate distribution and cooling turbine inlet temperature, all the various utilities required for year-round operation can be met both in Knoxville and in International Falls. Yet, the make-up air does not seem to quite match the demanding $I A Q$ requirements, particularly in the summer months.

The energy costs associated with the air cycle appear high as compared to conventional options both in Knoxville and in International Falls. Whereas situations with vast amounts of heating all-year round could be found, the position for acceptance in the fast-food environment appears difficult. Capital costs seem to also favor the conventional system. The absorption CHP systems offers interesting returns, and further consideration is recommended.

To help materialize the possibilities of the cycle, future work could involve a two-stage compression with intercooling. Raising the pressure ratio would increase the thermal efficiency, eliminate the recuperator and enable higher power turbine inlet temperature. Higher temperatures would require more sophisticated technology, such as turbine blade cooling. Precooling the compressor inlet air with the $c t$ turbine discharge (in lieu of reheating) deserves exploration. Another area of research is that of direct air injection with suitable humidity control. Finally, an electrical generator capable of both variable speed and motoring could be a development of considerable interest. 
Acknowledgement

The authors wish to acknowledge the support of the CHP DOE program, and of ORNL, for enabling the resources to complete this work. The sabbatical from Penn State awarded to H. Perez-Blanco was also instrumental in allowing the unconstrained time to characterize air cycles. The comments and suggestions of Dr. K. Gluesenkamp are warmly acknowledged.

References

[1]. Martinez I. , 2015. "Aircraft Environmental Control", in

http://webserver.dmt.upm.es/ isidoro/tc3/Aircraft\%20ECS.pdf

[2] Forster C.J., P. Lemiuex, 2011. "Development Of An Air-Cycle Environmental Control System For Automotive Applications." GT2011-46007 Proceedings of ASME Turbo Expo 2011

June 6-10, Vancouver, British Columbia, Canada.

[3] Zaki G.M , R. K. Jassim, M. M. Alhazmy, 2007. "Brayton Refrigeration Cycle For Gas Turbine Inlet Air Cooling”. Int. J. Energy Research, 2007; vol 31, pp 1292-1306.

[4] Foster A.M., T. Brown, A.J. Gigiel, A. Alford, J.A. Evans, 2011."Air Cycle Combined Heating And Cooling For The Food Industry". Int. J. Refrigeration vol 34 (2011) pp 1296-1304.

[5] Fleming J.S., B. J. C. Van Der Wekken,T, J. A. McGovern,U, R. J. M. Van Gerwen. 1998. "Air Cycle Cooling And Heating, Part 1: A Realistic Appraisal And A Chosen Application” Int. J. Energy Res., vol 22 , pp. 639-655 (1998).

[6] Al-Sulaiman F. A. F. Hamdullahpur, I. Dincer. 2011. "Trigeneration: A Comprehensive Review Based On Prime Movers”. Int. J. Energy Res. 2011; vol 35:pp 233-258.

[7] Baechler M., J. Williamson, T.Gilbride, P. Cole, M. Hefty and P. Love. 2010. VOLUME 7.1,HighPerformance Home Technologies: Guide to Determining Climate Regions by County, prepared for the D.O.E., Contract DE-AC05-76RLO 1830 PNNL-17211 http://apps1.eere.energy.gov/buildings/publications/pdfs/building_america/ba_climateguide_7_1.pdf

[8]Erdman J., Weather Channel, 2013. "5 Coldest Cities in America". https://weather.com/news/americas-5-coldest-cities\#/5

[9] Boyce M., 1993. "Principles of Operation and Performance Estimation of Centrifugal Compressors". 22 nd Turbomachinery Symp. Dallas, TX. Sept 14-16.

[10] Casey M., C. Robinson, 2013. "A Method to Estimate the Performance Map of a Centrifugal Compressor Stage”, J. of Turbomachinery, March 2013, Vol. 135 / 021034-1.

[11] A. Romagnoli A., R. Martinez-Botas, 2012, " Heat Transfer Analysis In A Turbocharger Turbine: An Experimental And Computational Evaluation" https://spiral.imperial.ac.uk/bitstream/10044/1/14305/2/Applied\%20Thermal\%20Engineering 38 2012.pdf

[12] Dixon S.L., C.A. Hall. 2014. Fluid Mechanics and Thermodynamics of Turbomachinery. $7^{\text {th }}$ Ed. Elsevier, Amsterdam.

[13] Payri F., J.R. Serrano , P. Fajardo, M.A. Reyes-Belmonte , R. Gozalbo-Belles . 2012." A physically based methodology to extrapolate performance maps of radial turbines". Energy Conversion and Management 55 (2012) 149-163. 
[14] Kays W. M., A. L. London, 1998. Compact Heat Exchangers, 3rd Edition, Krieger Publisihing CO., Malabar, FL.

[15] F-Chart Software, 2016. Engineering Equation Solver, EES. In http://www.fchart.com/ees/

[16] ABB Technical Specification, 2012. AMG 0200CC04 Application: Diesel/Gas Engine Industrial Application Series. https://library.e.abb.com/public/29f05231e36c6e7f48257a1c00087060/5862126-BAMG\%200200CC04\%20Technical\%20specification.pdf

[17] http://energy.gov/eere/buildings/commercial-reference-buildings

[18] Commercial and Residential Hourly Load Data Now Available in Open El 2015. http://en.openei.org/datasets/files/961/pub/COMMERCIAL LOAD DATA E PLUS OUTPUT/USA TN K noxville-McGhee.Tyson.AP.723260 TMY3/

[19] Energy.Gov. Office of Energy Efficiency and Renewable Energy. Reference Buildings by Building type: Quick Service Restaurant. 2015. http://energy.gov/eere/downloads/reference-buildings-buildingtype-quick-service-restaurant

[20] Energy Information Agency, 2016. http://www.eia.gov/electricity/sales revenue price/pdf/table4.pdf

[21] Energy Information Agency, Natural Gas, 2016.

http://www.eia.gov/dnav/ng/ng_pri_sum_dcu_STN_a.htm

[22] Commercial and Residential Hourly Load Data Now Available in Open El 2015

http://en.openei.org/datasets/dataset/commercial-and-residential-hourly-load-profiles-for-all-tmy3locations-in-the-united-states/resource/b341f6c6-ab5a-4976-bd07-adc68a2239c4

[23] EIA, 2016. https://www.eia.gov/electricity/monthly/epm_table_grapher.cfm?t=epmt_5_6_a

[24] RS Means 2015. Mechanical Cost Data 2015 38 ${ }^{\text {th }}$ Annual Edition, Mossman M.J. (Editor), C. Babbitt C. (Editor), A. C. Charest (Editor), G. W. Christensen (Editor), B. Mewis (Contributor).

[25] Hansen H. 2016. “Compare Gas Furnace Prices”. http://www.furnacepriceguides.com/gas-furnace/ [26] http://www.amazon.com/Rheem-G100-200-Natural-Universal-Commercial/dp/B0019LVIKA

[27] Cooling Tower Systems Price Guide, http://www.coolingtowersystems.com/pdfs/ListPriceGuide.pdf

[28] Capehart, B. L., 2014. "Microturbines" Whole Building Design Guide-National Institute of Building Sciences. https://www.wbdg.org/resources/microturbines.php

[29]. Robur, 2016. GA ACF ST\& TK. http://www.roburcorp.com/chillers/gas_absorption_chiller_ga_acf 
Table 1. Radial turbine efficiency correlation.

\begin{tabular}{|c|c|}
\hline $\mathrm{a}_{0}$ & 4.951 \\
\hline $\mathrm{a}_{1}$ & -22.358 \\
\hline $\mathrm{a}_{2}$ & 1.232 \\
\hline $\mathrm{a}_{12}$ & 0.354 \\
\hline $\mathrm{a}_{11}$ & 38.113 \\
\hline $\mathrm{a}_{22}$ & -2.346 \\
\hline $\mathrm{a}_{112}$ & 0.421 \\
\hline $\mathrm{a}_{122}$ & -0.454 \\
\hline $\mathrm{a}_{111}$ & 21.142 \\
\hline $\mathrm{a}_{222}$ & 1.6 \\
\hline
\end{tabular}


Table 2 Example conditions for direct TCA air injection.

\begin{tabular}{|l|c|c|c|c|c|}
\hline & $\mathrm{mfr}, \mathrm{kg} / \mathrm{s}$ & Dry bulb, C & Wet bulb, C & ah & $\mathrm{h}, \mathrm{J} / \mathrm{kg}$ \\
\hline RA & 0.5 & 23.3 & 16.5 & 0.00893 & 22694 \\
\hline SA & 0.5 & -73.2 & -73.2 & 0 & -28168 \\
\hline
\end{tabular}


Table 3. Assumed and calculated variables for simulation.

\begin{tabular}{|l|c|c|c|c|}
\hline Variable & Compressor & Cooling turb. & Power turb. & SCCHP \\
\hline Speed, rpm & 66845 & 66845 & 66845 & \\
\hline Inlet temperature, K & 288 & 551 & 1250 & \\
\hline Mass flow rate, kg/s & 1.00 & 0.5 & 0.5 & \\
\hline Isentropic efficiency & 0.71 & 0.88 & 0.87 & \\
\hline Power, kW & 222 & 53 & 188 & \\
\hline Impeller/runner dia, m. & 0.18 & 0.095 & 0.18 & \\
\hline Pressure ratio & & & & 4.5 \\
\hline Net power, kW & & & & 20 \\
\hline Cooling capacity, kW & & & & 12.7 \\
\hline Heating capacity, $\mathrm{kW}$ & & & & 273 \\
\hline
\end{tabular}




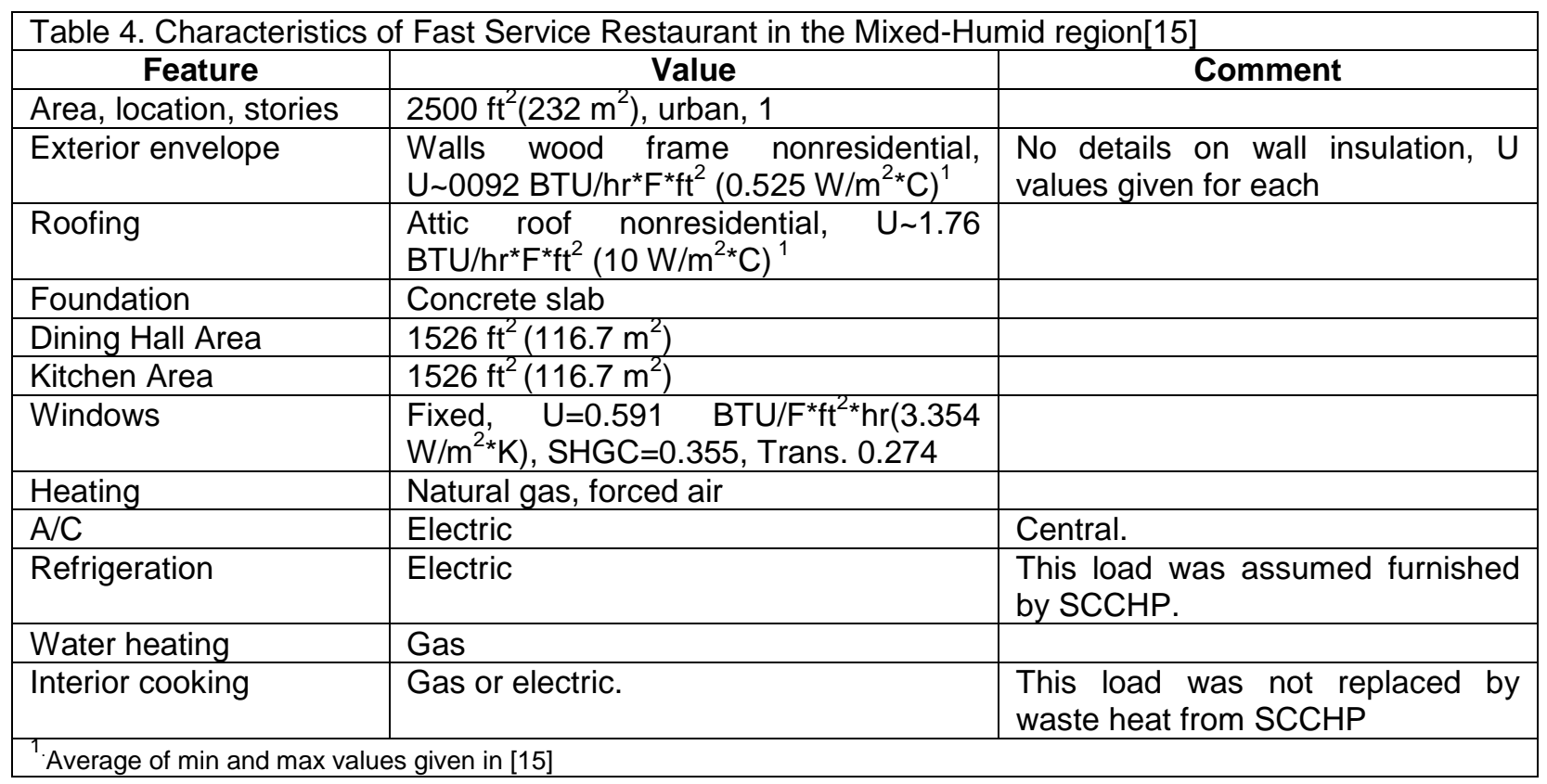




\begin{tabular}{|c|c|c|c|c|c|c|c|c|}
\hline Day, hr & $\begin{array}{l}\mathrm{A} / \mathrm{C} \\
\mathrm{kW}\end{array}$ & $\begin{array}{l}\text { Power } \\
\text { kW }\end{array}$ & $\begin{array}{l}\text { Heating } \\
\text { kW }\end{array}$ & $\begin{array}{c}\text { Power }{ }^{1} \text { rate, } \\
\text { c/kW*hr }\end{array}$ & $\begin{array}{l}\text { Gas rate, } \\
\$ / \mathrm{Kw}^{\star} \mathrm{hr}^{3}\end{array}$ & $\begin{array}{c}\text { Cost } \\
\text { convent., \$ }\end{array}$ & $\begin{array}{l}S C C H P \\
\text { cost }, \$^{2,4}\end{array}$ & $\begin{array}{c}\text { Cost } \\
\text { abs/lC } \\
\$^{2,4,5,6}\end{array}$ \\
\hline $8 / 15,5$ & 1.8 & 26.1 & 1.0 & 0.1142 & 0.032 & 3.22 & 7.54 & 2.29 \\
\hline $8 / 15,12$ & 12.8 & 23.9 & 2.1 & 0.1246 & 0.032 & 2.98 & 9.76 & 2.32 \\
\hline $8 / 15,17$ & 10.3 & 23.9 & 3.1 & 0.1349 & 0.032 & 3.21 & 9.57 & 2.12 \\
\hline $1 / 02,5$ & 0 & 18.1 & 38.7 & 0.1246 & 0.032 & 3.49 & 6.58 & 2.21 \\
\hline $1 / 02,19$ & 0 & 26.1 & 26.1 & 0.1194 & 0.032 & 3.48 & 8.03 & 2.28 \\
\hline $\begin{array}{ll}1 . & \mathrm{P} \\
2 . & \mathrm{A} \\
3 . & \mathrm{G} \\
4 . & \mathrm{B} \\
5 . & \mathrm{A} \\
6 . & \mathrm{G}\end{array}$ & $\begin{array}{l}\text { er price } \\
\text { excess } p \\
\text { prices, } 2 \\
\text { er efficie } \\
\text { rption } m \\
\text { fired ens }\end{array}$ & $\begin{array}{l}\text { se is } 10.38 \\
\text { wer credite } \\
14 \text {, ElA [21 } \\
\text { y of } 0.9 \text {. } \\
\text { chine COP } \\
\text { te is } 30 \mathrm{~kW}\end{array}$ & $\begin{array}{l}6,0.57 \text { and } \\
\text { running con }\end{array}$ & $\begin{array}{l}.55 \text { at each Su pe } \\
\text { luously with } 0.35\end{array}$ & al efficiency. & 1.2 , and 1.3 . & & \\
\hline
\end{tabular}




\begin{tabular}{|c|c|c|c|c|c|c|c|}
\hline \multicolumn{8}{|c|}{$\begin{array}{l}\text { Table } 6 \text {. Costs of providing utilities to fast food restaurant, International Falls, MN. } \\
\text { (2014 prices) }\end{array}$} \\
\hline Day, hr & $\begin{array}{l}\mathrm{A} / \mathrm{C} \\
\mathrm{kW}\end{array}$ & $\begin{array}{l}\text { Power } \\
\mathrm{kW}\end{array}$ & $\begin{array}{l}\text { Heating } \\
\mathrm{kW}\end{array}$ & $\begin{array}{l}\text { Power }^{1} \\
\text { rate, } \\
\text { c/kW*hr }\end{array}$ & $\begin{array}{l}\text { Gas rate, } \\
\$ / K w^{*} r^{3}\end{array}$ & $\begin{array}{l}\text { Cost } \\
\text { Conventional \$ }\end{array}$ & $\begin{array}{l}\text { SCCHP } \\
\text { cost }, \$\end{array}$ \\
\hline $1 / 2,9 \mathrm{am}^{4}$ & 0 & 18.31 & 80.4 & 0.1141 & 0.0295 & 4.46 & 5.82 \\
\hline $8 / 15,12 \mathrm{pm}^{4}$ & 4.4 & 24.1 & 3.2 & 0.1141 & 0.0295 & 3.34 & 5.99 \\
\hline \multicolumn{8}{|c|}{$\begin{array}{l}\text { 1. Power price base is } 9.51 \mathrm{c} / \mathrm{kW}^{*} \mathrm{hr}[23] \text {, with peak demand factor of 1.2. December } 2014 . \\
\text { 2. No excess power is credited. } \\
\text { 3. Gas prices, 2014, EIA [21], Burner efficiency of } 0.9 \text {. }\end{array}$} \\
\hline 4. Adopted inlet & & temperat & e winter & mer , 28 & & & \\
\hline
\end{tabular}




\begin{tabular}{|c|c|}
\hline \multicolumn{2}{|c|}{ Table 7. Simulation results with larger compressor. } \\
\hline Variable & Value \\
\hline $\mathrm{T}_{\mathrm{o1c}}, \mathrm{K}$ & 280 \\
\hline $\mathrm{mfr}_{\mathrm{c}}, \mathrm{kg} / \mathrm{s}$ & 1.32 \\
\hline $\mathrm{mfr}_{\mathrm{ct}}, \mathrm{kg} / \mathrm{s}$ & 0.66 \\
\hline $\mathrm{mfr}_{\mathrm{pt}}, \mathrm{kg} / \mathrm{s}$ & 0.66 \\
\hline$\dot{Q}_{C}, \mathrm{~kW}$ & 25.8 \\
\hline$\dot{Q}_{H}, \mathrm{~kW}$ & 5 (out of max 118) \\
\hline$\dot{W}, \mathrm{~kW}$ & 25.2 \\
\hline$\dot{Q}_{\text {inp }}, \mathrm{kW}$ & 292.6 \\
\hline
\end{tabular}




\begin{tabular}{|c|c|c|c|c|}
\hline \multicolumn{5}{|c|}{$\begin{array}{l}\text { Table } 8 \text {. Estimate of capital costs for conventional, CHP absorption and SCCHP systems. Fast foo } \\
\text { restaurant, } 2500 \mathrm{ft}^{2} \text {. }\end{array}$} \\
\hline System & Component, capacity & Unit cost & Total installed cost, $\$$ & Source \\
\hline \multirow[t]{4}{*}{ Conventional } & $\mathrm{A} / \mathrm{C}, 44 \mathrm{~kW}$ & $\$ 14 / \mathrm{ft}^{2}$ & 35000 & [24] \\
\hline & Forced air furnace, $45 \mathrm{~kW}$ & & 7500 & [25] \\
\hline & Water heater, $100 \mathrm{gal}$ & & 3840 & [26] \\
\hline & Ducting/conditioning & $\$ 5 / \mathrm{ft}^{2}$ & 12500 & [24] \\
\hline \multicolumn{3}{|c|}{ Total conventional } & 58,840 & \\
\hline System & Component, capacity & Unit cost & Total installed cost, \$ & Source \\
\hline \multirow[t]{5}{*}{$\begin{array}{c}\text { CHP } \\
\text { absorption }\end{array}$} & Gen-set, 30 kW & & 17350 & [24] \\
\hline & Absorption A/C, $44 \mathrm{~kW}$ & & 33450 & [24] \\
\hline & Cooling tower ${ }^{a}, 120 \mathrm{~kW}$ & & 5810 & [27] \\
\hline & $\begin{array}{l}\text { Heat recovery w/duct burner, } \\
45 \mathrm{~kW}\end{array}$ & & 15530 & [24] \\
\hline & Ducting/conditioning & & 12500 & [24] \\
\hline \multicolumn{3}{|c|}{ Total absorption } & 84640 & \\
\hline System & Component, capacity & Unit cost & Total installed cost, \$ & Source \\
\hline \multirow[t]{4}{*}{ SCCHP } & Power, $28 \mathrm{kWe}$ & \multirow{3}{*}{$\begin{array}{c}\$ 800 / \mathrm{kWe} \cdot 1 . \\
5 \cdot 1.5\end{array}$} & & \\
\hline & $\dot{Q}_{C}, 25 \mathrm{~kW}$ & & & \\
\hline & $\dot{Q}_{H}, 45 \mathrm{~kW}$ & & 50400 & [28] \\
\hline & Ducting/conditioning & $\$ 5 / \mathrm{ft}^{2}$ & 12500 & [24] \\
\hline \multicolumn{3}{|c|}{ Total SCCCHP } & 62,900 & \\
\hline
\end{tabular}




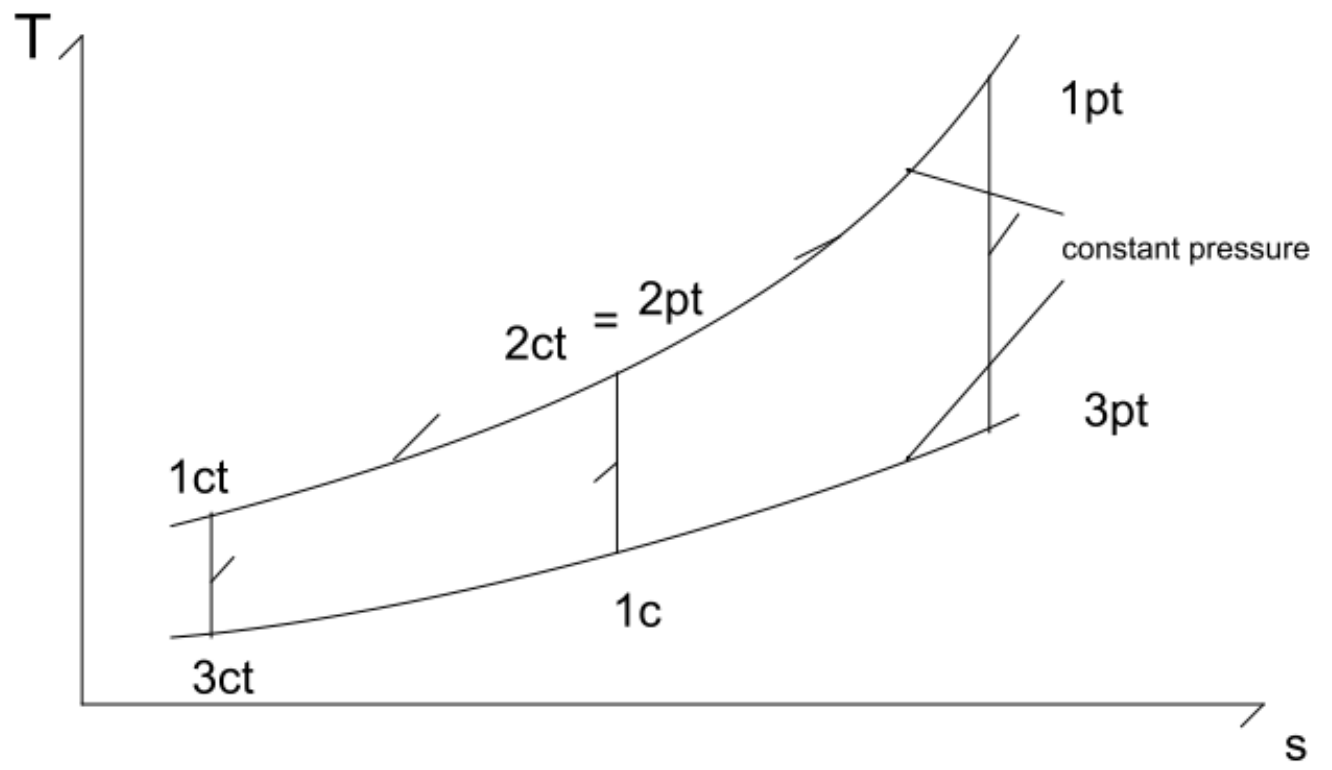

Figure 1. Brayton cycle (1-2pt-1pt-3pt) and reverse Brayton cycle (1-2ct-1ct-3ct) for an ideal gas. Note that the temperature of $3 \mathrm{ct}$ is below that of 1 . 


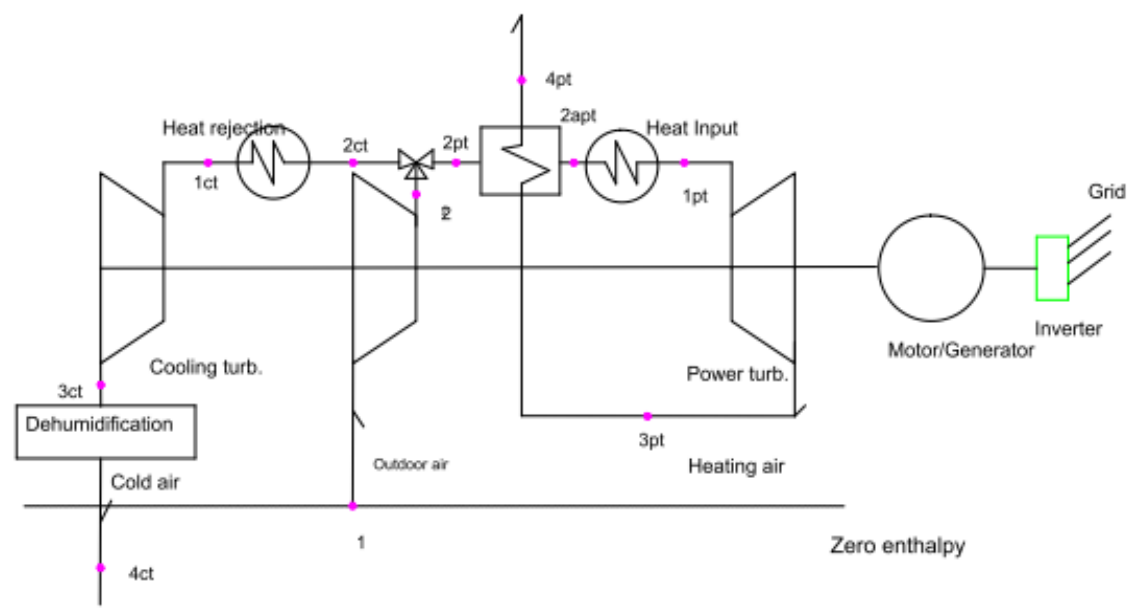

Figure 2. The schematic of an air cycle for trigeneration shows all rotating components on the same shaft. 


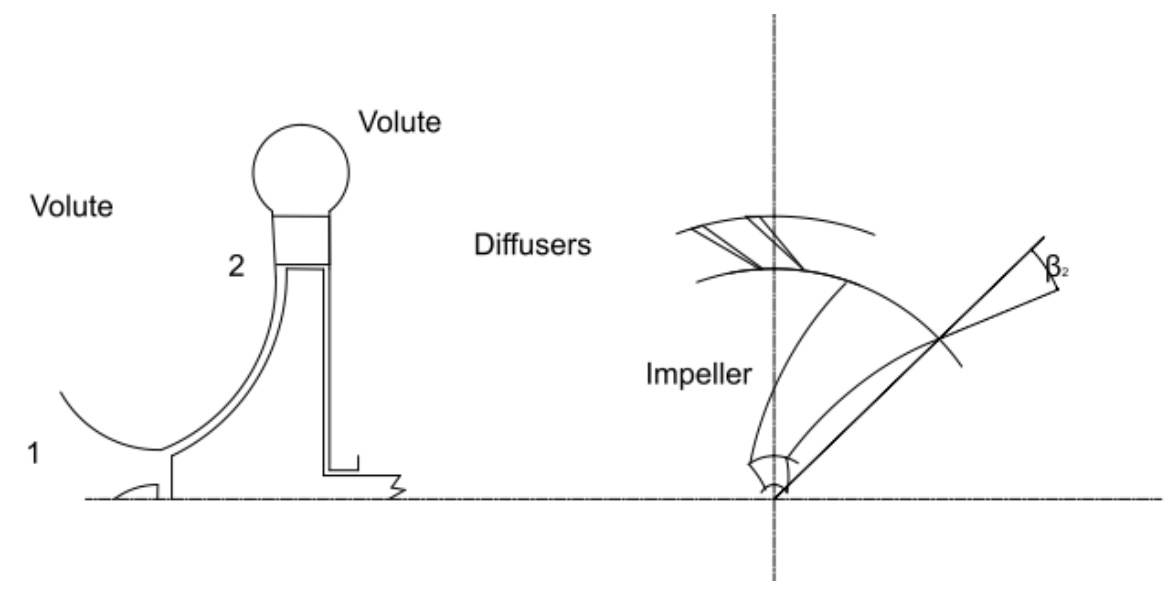

Figure 3. Schematic of centrifugal compressor, counterclockwise rotation. 


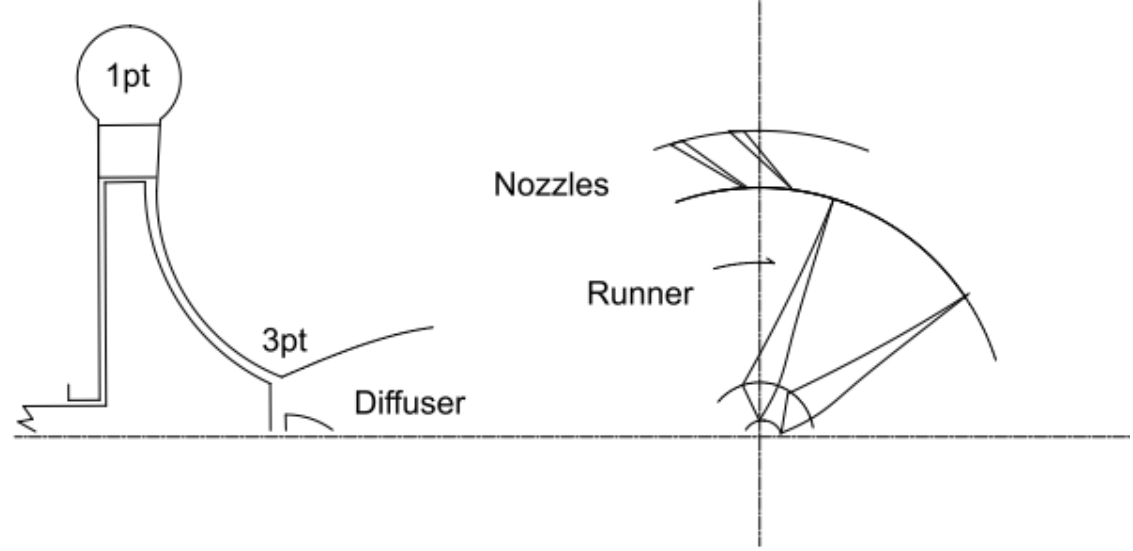

Figure 4. Schematic of radial turbine, clockwise rotation. Rotational direction can be inverted by changing nozzle and vane orientation. 


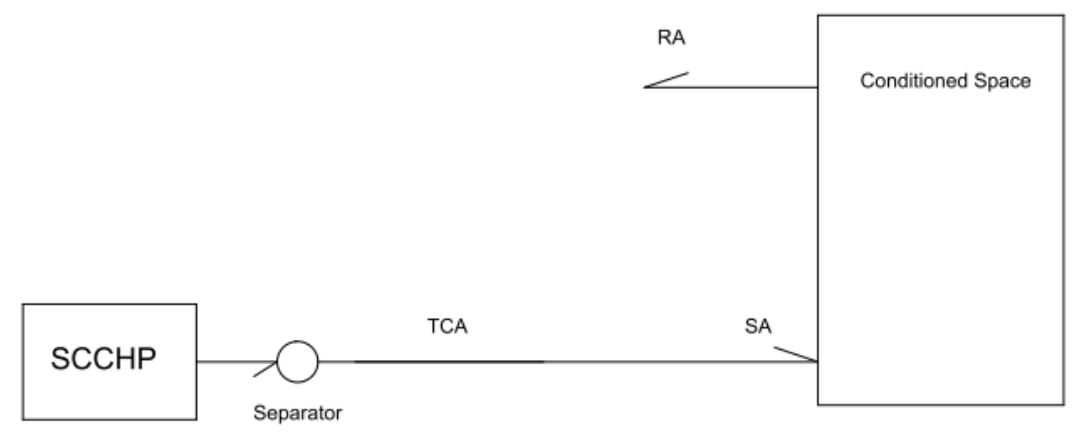

Figure 5. In direct injection, the exhaust air from the cooling turbine is directly injected in the conditioned space. 


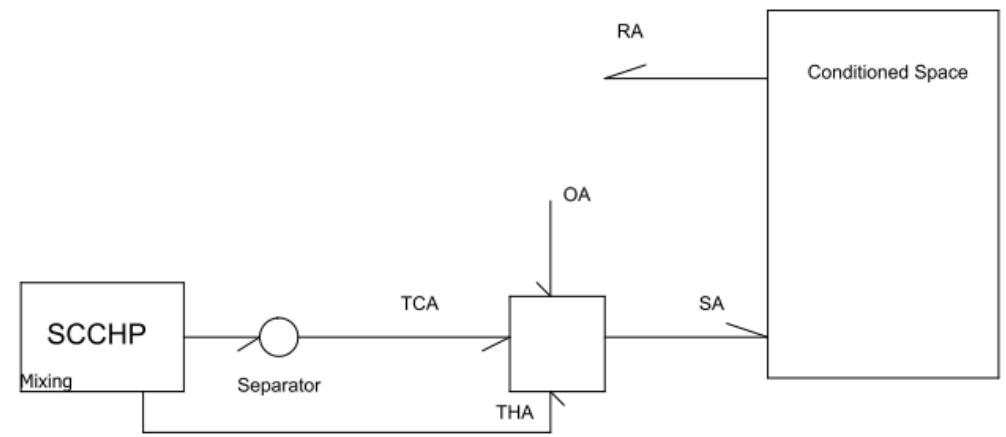

Figure 6. In order to furnish supply air at conventional conditions, the turbine exhaust air must be mixed with outdoor air and reheated. 


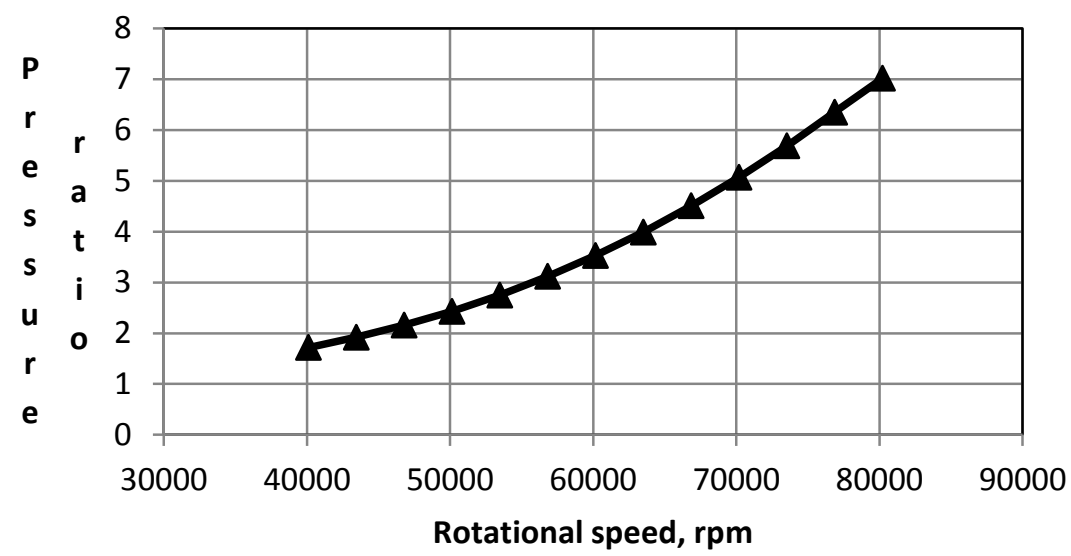

$\longrightarrow$ Pressure ratio

Figure 7. The pressure ratio increases parabolically with the tip velocity. 


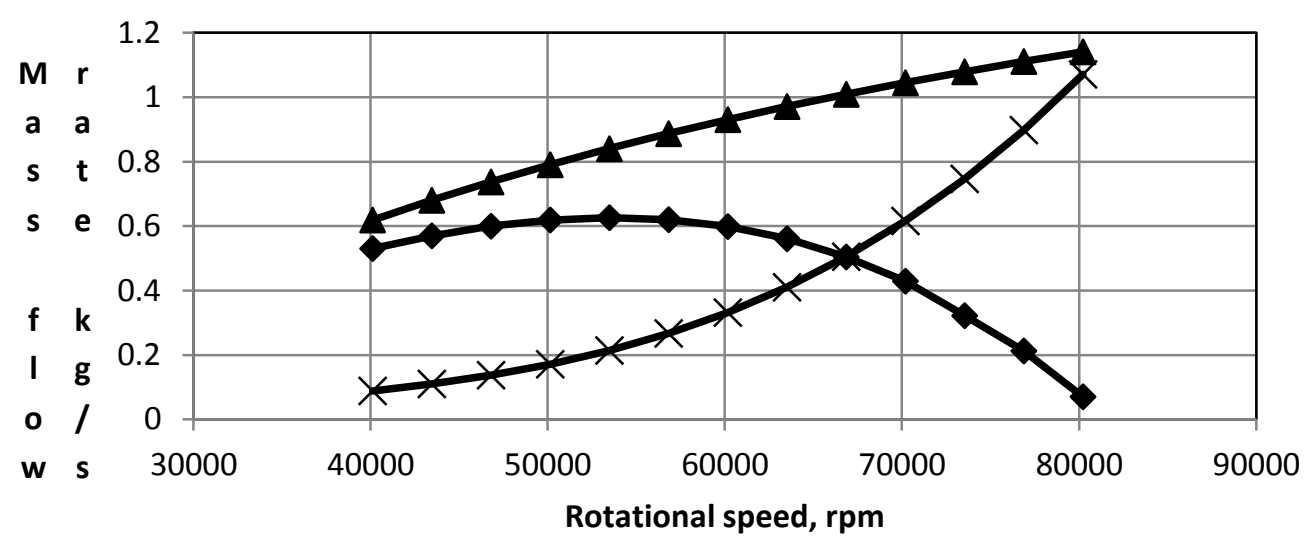

$*$ Cooling turbine mass flow rate $\longrightarrow$ Power turbine mass flow rate $\longrightarrow$ Compressor mass flow rate

Figure 8. Calculated mass flow rates vs. speed. 


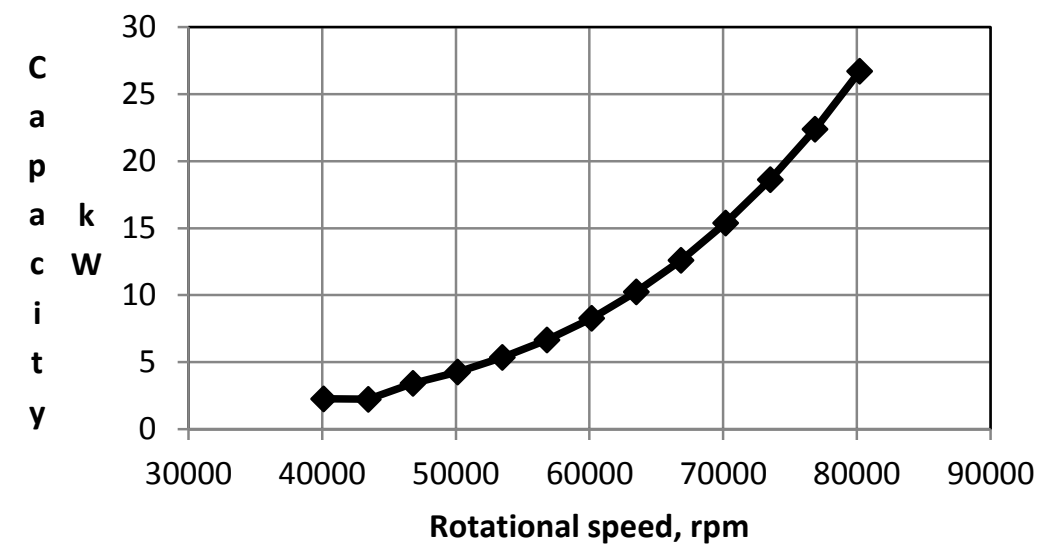

-Cooling capacity

Figure 9. The supply air cooling capacity increases with rotational speed. 


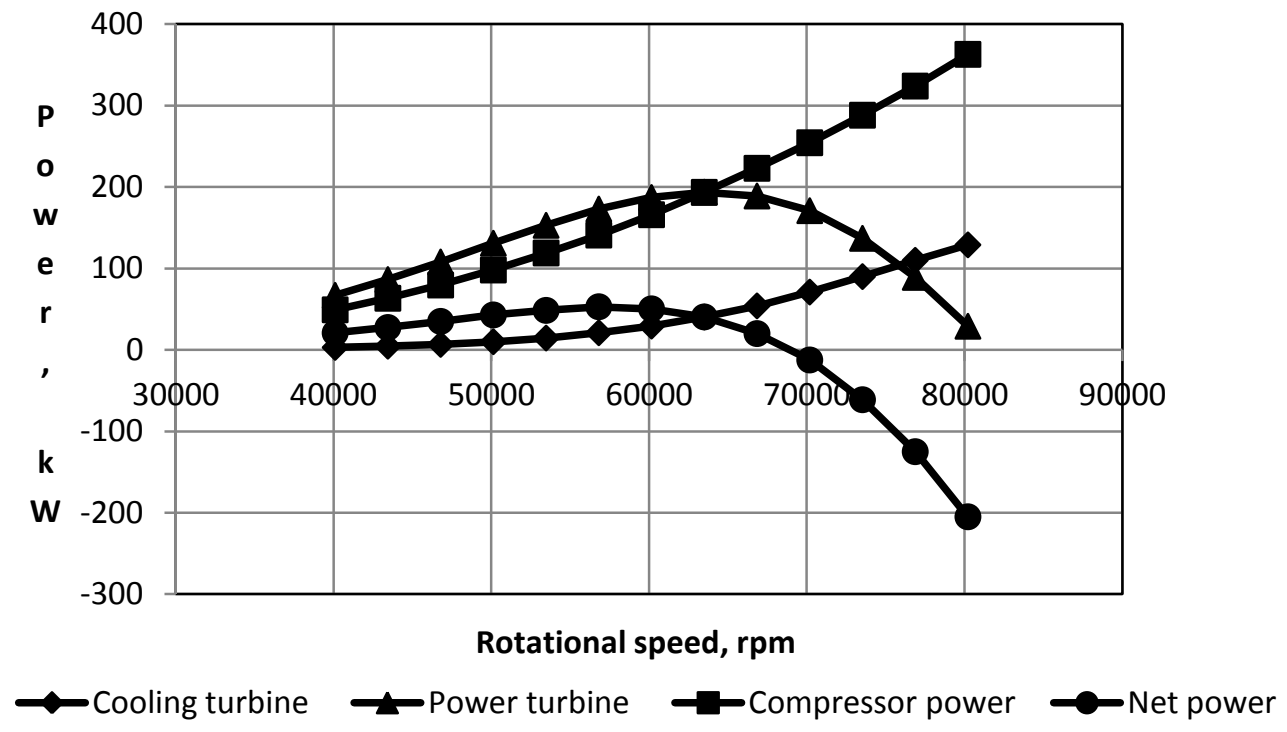

Figure 10. The compressor demands power, and the net power is positive for speeds below $70000 \mathrm{rpm}$. 


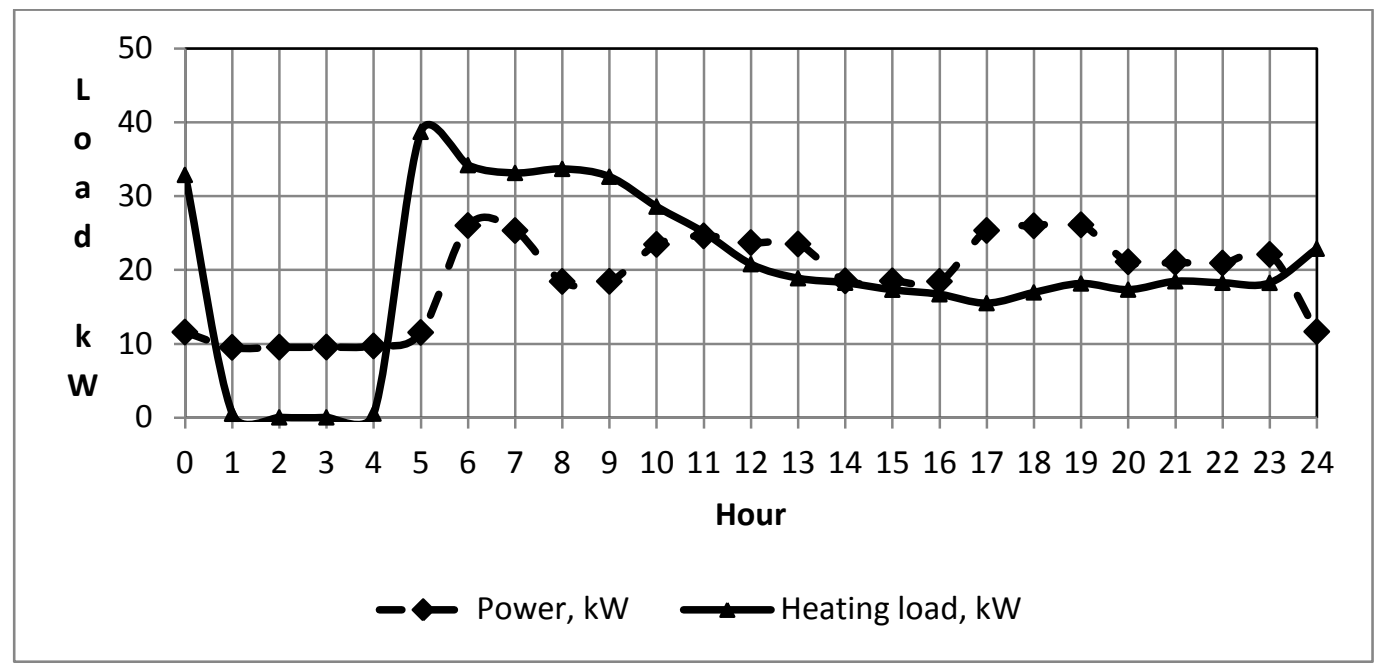

Figure 11. Winter day load profile, showing a large heating peak in the morning. 


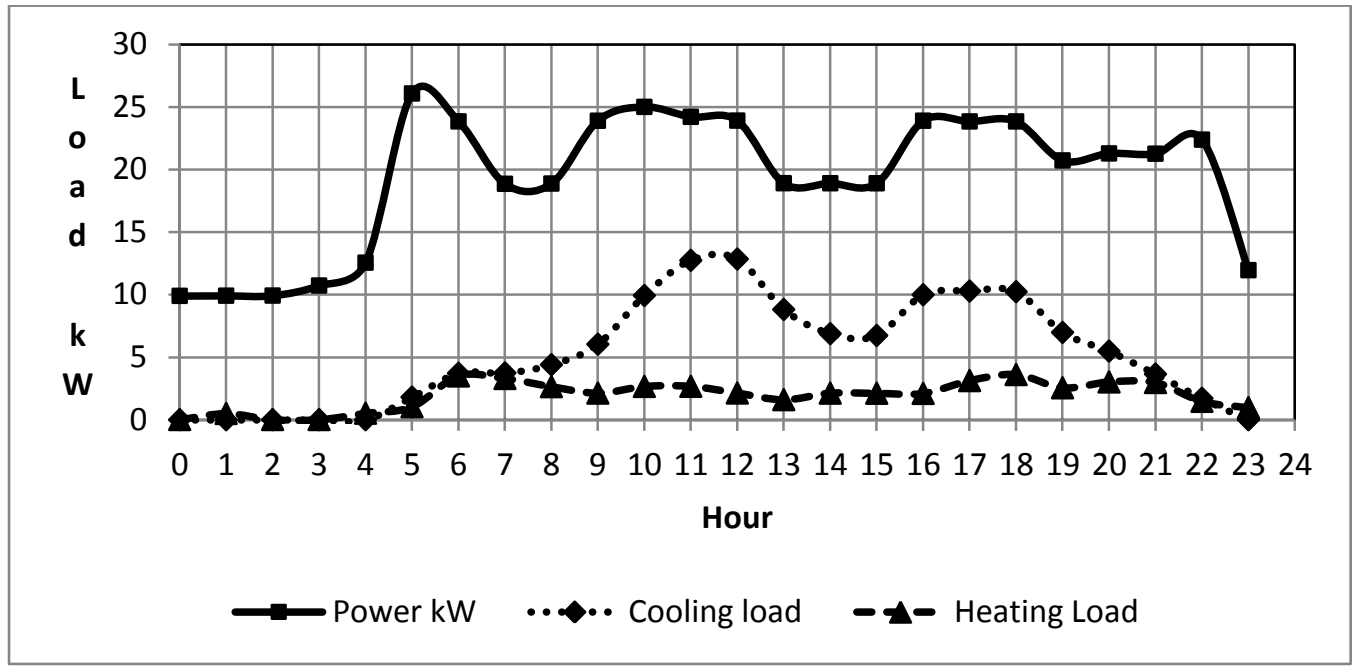

Figure 12. Summer loads, with the cooling load exhibiting two peaks, one at noon, one at $17 \mathrm{hrs}$, and the power one peak at $5 \mathrm{hrs}$. 


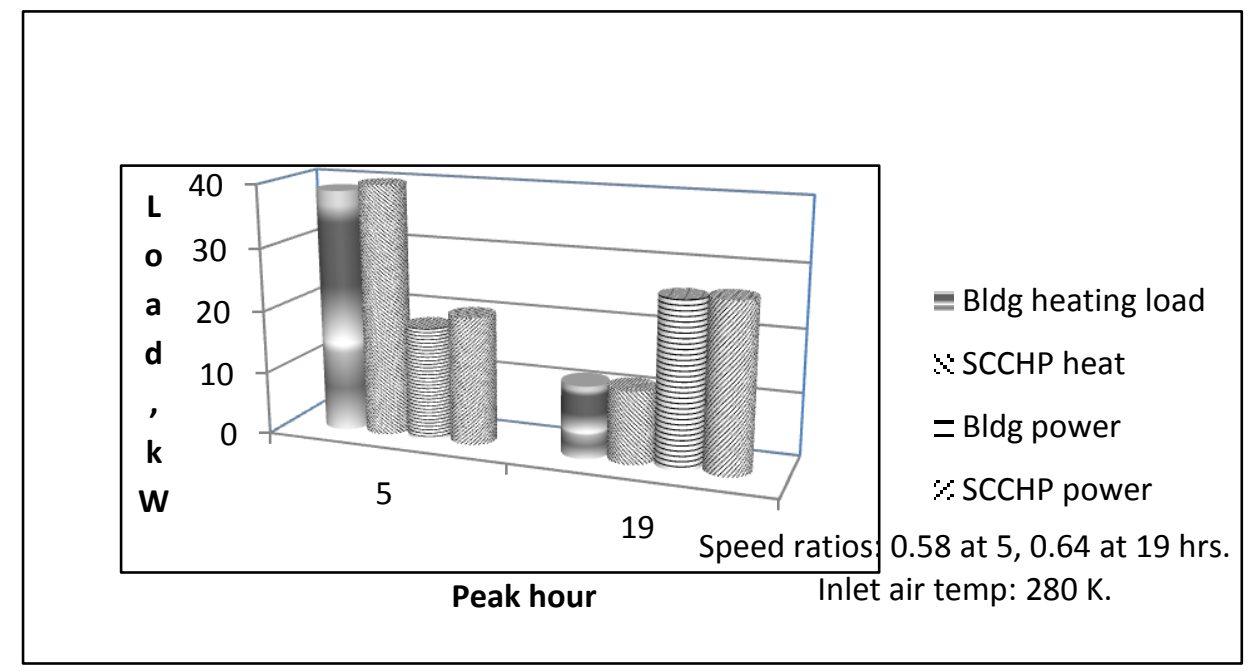

Figure 13. Winter loads could be easily met by SCCHP. 


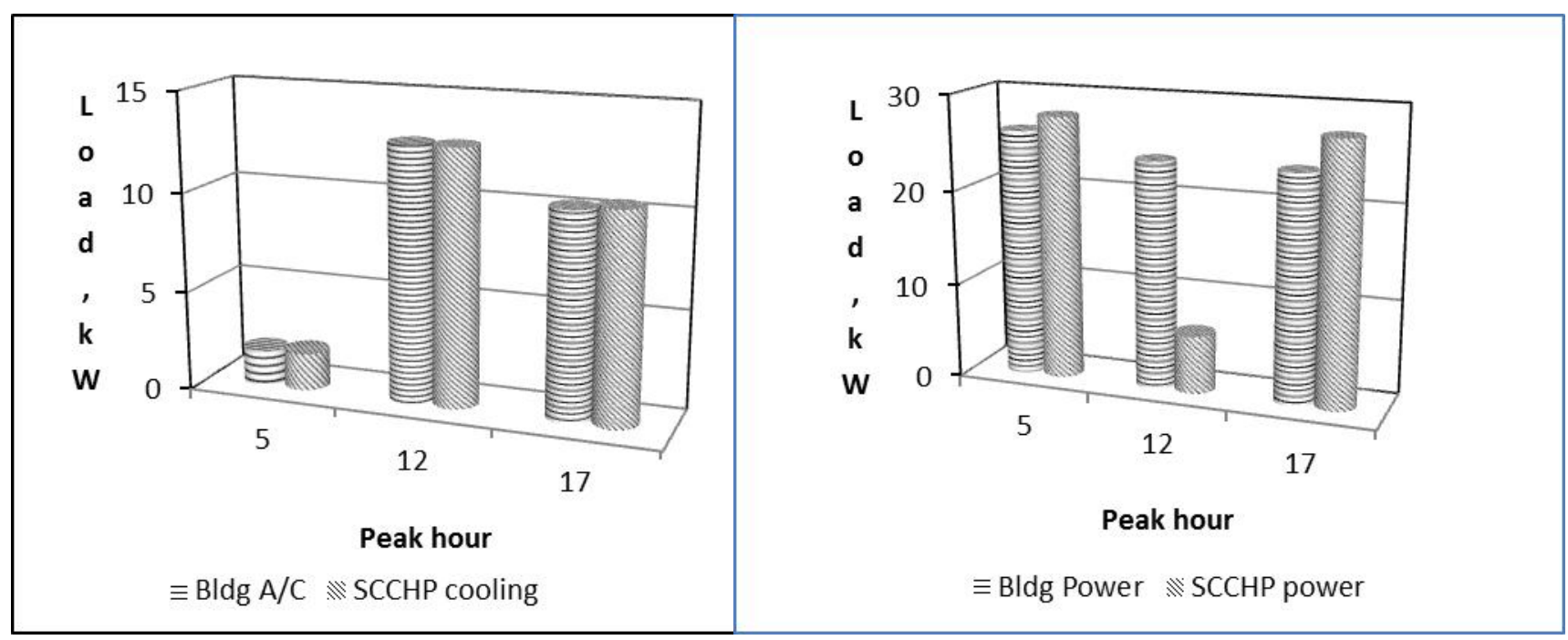

(a)

(b)

Figure 14 (a). A/C building load is met at all 3 peak hours of Fig. 12. (b) Power peaks are met by SCCHP only at 5 and $17 \mathrm{hrs}$. Speed ratios: $0.68,0.95,1$ at $5,12 \& 17 \mathrm{hrs}$. Mass ratios:0.11, 0.53, 0.42 at 5,12 \& $17 \mathrm{hrs}$. Inlet air temp: $295 \mathrm{~K}$ 


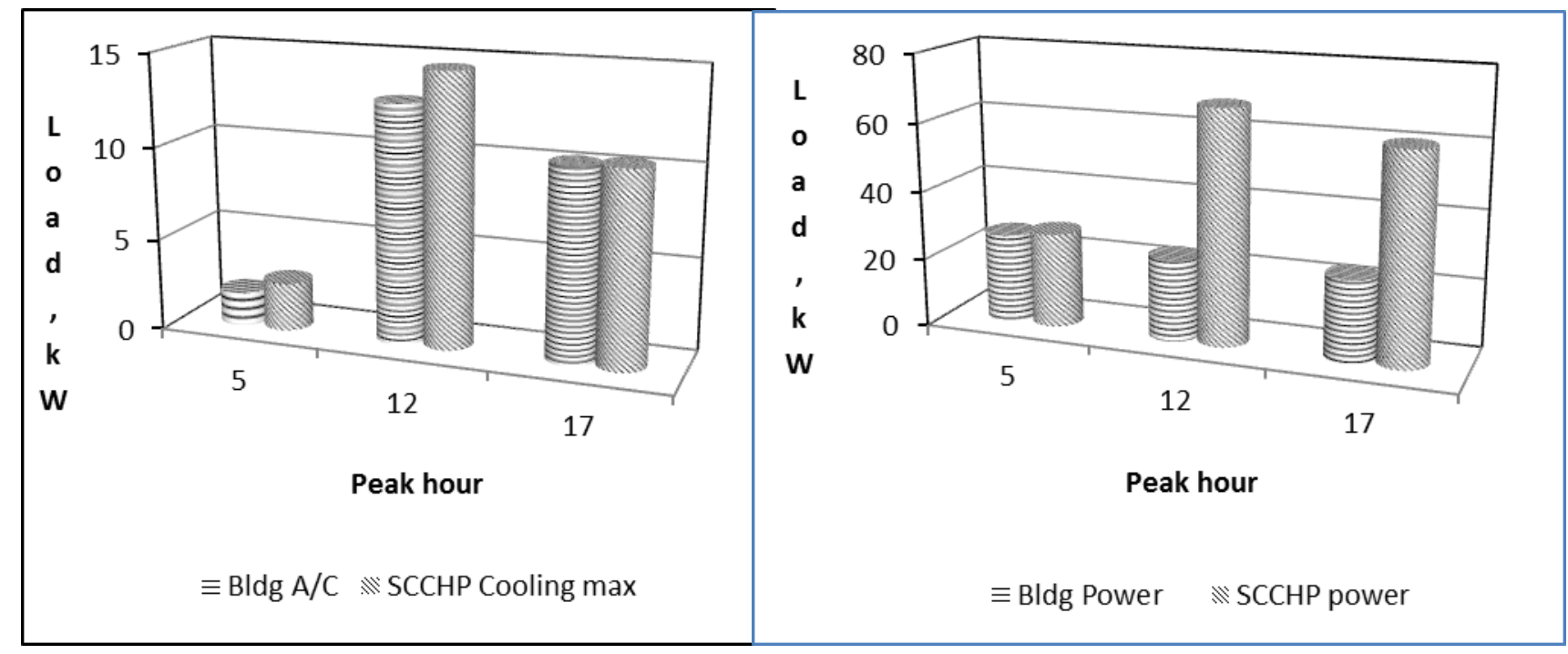

(a)

(b)

Figure 15. When direct air injection is used, both the building $A / C$ and power loads are met or exceeded at all Su peak hours. 